\title{
Penandaan Otomatis Tempat Parkir Menggunakan YOLO untuk Mendeteksi Ketersediaan Tempat Parkir Mobil pada Video CCTV
}

\author{
${ }^{1}$ Evan Tanuwijaya, ${ }^{2}$ Chastine Fatichah \\ ${ }^{1,2}$ Departemen Teknik Informatika, Institut Teknologi Sepuluh Nopember, \\ Surabaya, Indonesia
}

Email: ${ }^{1}$ evantanuwijaya.18051@mhs.its.ac.id, ${ }^{2}$ chastine@if.its.ac.id

\begin{tabular}{l}
\hline Tersedia Online di \\
\hline http://www.jurnal.unublitar.ac.id/ \\
index.php/briliant
\end{tabular}

\section{Sejarah Artikel}

Diterima pada 17 Januari 2020

Disetuji pada 23 Januari 2020

Dipublikasikan pada 29 Februari 2020 Hal. 189- 198

\begin{tabular}{l}
\hline Kata Kunci: \\
\hline $\begin{array}{l}\text { Deep learning; Deteksi } \\
\text { ketersediaan parkir mobil; Image } \\
\text { processing; CNN; YOLO V3 }\end{array}$ \\
\hline DOI: \\
\hline http://dx.doi.org/10.28926/briliant \\
.v3i4.434
\end{tabular}

\begin{abstract}
Abstrak: Sulitnya menemukan tempat parkir terutama saat jam sibuk adalah masalah yang umum dialami oleh pengemudi. Banyak penelitian untuk mendeteksi ketersediaan tempat parkir memanfaatkan CCTV. Namun, penelitian tersebut memiliki beberapa masalah seperti mendeteksi tempat parkir dilakukan secara manual menjadi tidak efisien ketika diterapkan pada tempat parkir yang berbeda. Oleh karena itu, penelitian ini menggunakan YOLO V3 untuk mendeteksi secara otomatis tempat parkir pada data CCTV kemudian diklasifikasikan terisi atau tidak. Hasil terbaik penandaan menggunakan YOLO V3 yaitu saat kondisi cuaca mendung dengan nilai akurasi ratarata 94,49\%. Hasil klasifikasi didapatkan nilai terbaik pada arsitktur Alexnet dengan rata-rata akurasi $93,48 \%$.
\end{abstract}

\section{PENDAHULUAN}

Pengenalan objek dalam bidang computer vision (Voulodimos, Doulamis, Doulamis, \& Protopapadakis, 2018) untuk kegiatan bermasyarakat sudah berkembang pesat. Berbagai metode dari hasil penelitian sudah banyak digunakan untuk membantu kegiatan di masyarakat. Semakin banyaknya data citra yang ada, maka pengenalan objek ini sangat dibutuhkan untuk mempermudah mengenali objek pada citra tersebut dalam waktu yang relatif cepat. Pengenalan objek pada citra ini banyak digunakan untuk mengenali tulisan (Borisyuk, Gordo, \& Sivakumar, 2018), mobil (Liang et al., 2018), sidik jari (Lin \& Kumar, 2018), wajah (Sugianto, Tjondronegoro, \& Tydd, 2018), dan lain-lain. Beberapa peneliti menerapkan pengenalan objek untuk mendeteksi ketersediaan tempat parkir mobil pada sebuah lapangan parkir. Penelitian ini dilakukan karena banyak pengendara mobil di kota-kota besar kesulitan dalam mencari ketersediaan lapangan parkir terutama pada jam sibuk. Ketika lapangan parkir tersebut tersedia, pengendara mobil akan saling berebut lapangan parkir (Geitgey, 2019; Yusnita, Fariza, \& Norazwinawati, 2012). Oleh sebab itu, pengenalan objek menggunakan deep learning digunakan untuk mengatasi masalah. Dengan menggunakan data video dari CCTV yang ditempatkan di beberapa bagian, pengenalan objek 
menggunakan deep learning dapat mengenali ketersediaan tempat parkir tanpa perlu memasang CCTV di tempat parkir.

Telah banyak penelitian yang dilakukan terkait deteksi ketersediaan tempat parkir mobil menggunakan data citra. Penelitian yang dilakukan oleh (Amato et al., 2017) untuk mendeteksi ketersediaan lapangan parkir menggunakan CNN Alexnet yang dimodifikasi dengan mengurangi layer konvolusinya menjadi mini Alexnet memiliki tingkat akurasi yang tinggi dalam mendeteksi ketersediaan lapangan parkir. Akan tetapi pada penelitian tersebut tidak dijelaskan bagaimana langkah untuk mendapatkan posisi lapangan parkir.

Oleh sebab itu, dalam penelitian ini akan menerapkan metode You Only Look Once (YOLO) V3 untuk mendeteksi posisi tempat parkir yang ada pada lapangan parkir kemudian membuat penanda pada tempat parkir tersebut. Setelah tempat parkir pada lapangan parkir tersebut ditandai, masing-masing penanda akan diklasifikasikan apakah tempat parkir tersebut terisi atau tidak.

\section{METODE}

Pada bab ini juga akan dibahas mengenai sistem untuk mendeteksi ketersediaan tempat parkir yang akan dibuat. Untuk dapat mendeteksi tempat parkir mobil, penelitian ini mengembangkan sebuah strategi sistem. Strategi tersebut merupakan pengembangan dari penelitian (Amato et al., 2017; Geitgey, 2019) dalam hal deteksi tempat parkir otomatis dan CNN dengan jumlah parameter yang lebih kecil. Pada penelitian ini, strategi yang akan dibuat memiliki 2 tahap utama yaitu tahap marking dimana sistem akan diberi masukan citra tempat parkir yang penuh dengan mobil yang terparkir untuk ditandai. Selanjutnya tahap klasifikasi di mana pada proses tempat parkir yang telah ditandai dari proses marking akan diklasifikasikan ketersediaan tempat parkir pada lapangan parkir dengan masukan berupa citra atau video dari CCTV. Oleh sebab itu, pada bab ini akan dibahas mengenai sistem yang akan dibuat, seperti pada Gambar 1. Sesuai dengan yang dijabarkan sebelumnya. Sistem dari penelitian ini memiliki dua tahap utama yaitu marking dan klasifikasi yang akan dijabarkan pada sub bab berikut.

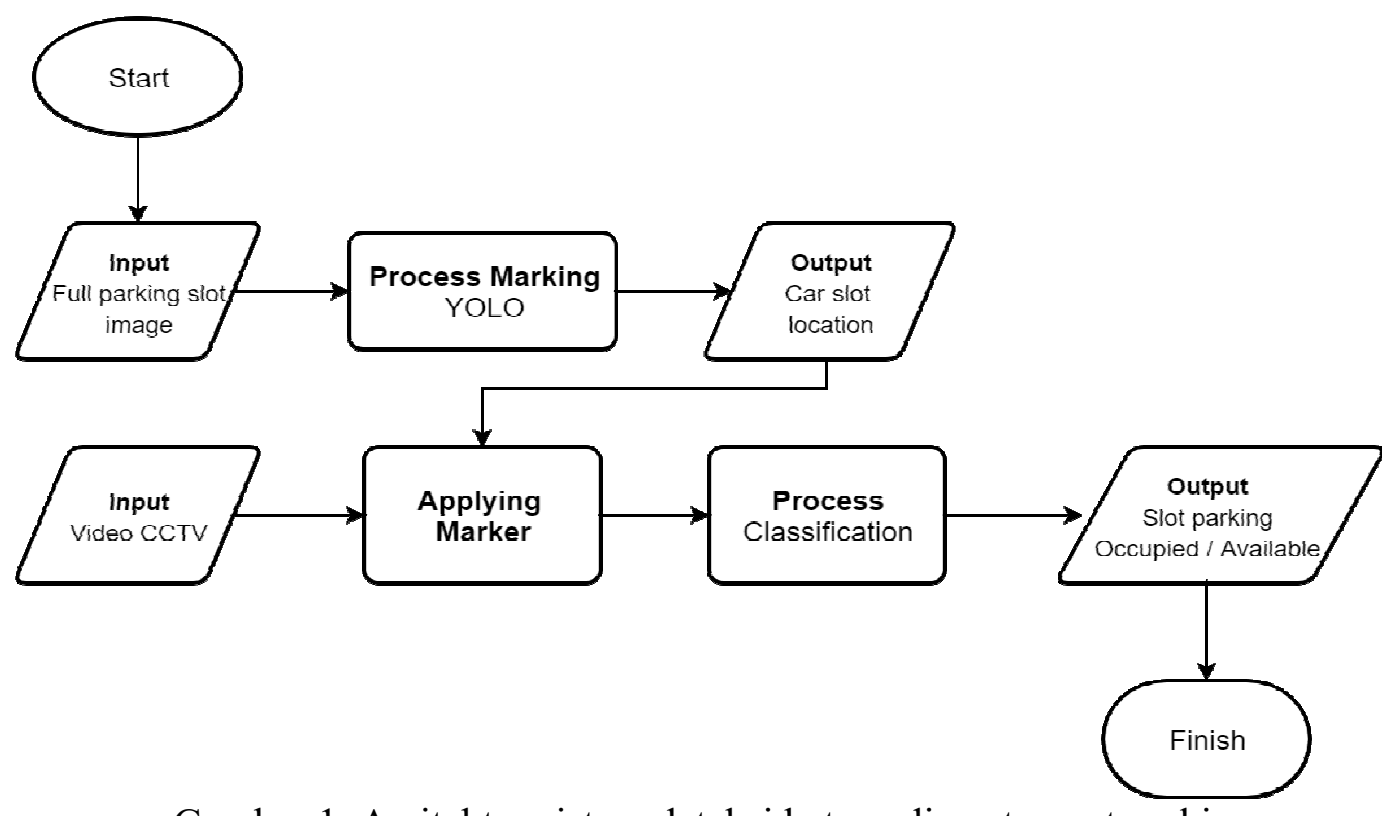

Gambar 1. Arsitektur sistem deteksi ketersediaan tempat parkir 
Pada penelitian ini, diperlukan dua data yang pertama adalah citra lapangan parkir yang telah penuh terparkir oleh mobil untuk tahap marking dan kedua adalah video rekaman dari CCTV untuk melakukan deteksi ada tidaknya tempat parkir pada lapangan tersebut. Tahap marking merupakan tahap yang dilakukan untuk mengetahui seluruh posisi lapangan parkir yang ada sehingga tahap ini tidak perlu dilakukan berulang kali. Adapun tahap marking ditunjukkan oleh Gambar 2. Untuk dataset yang akan digunakan adalah citra dan video dari CCTV yang berada pada lapangan parkir. Lapangan parkir yang telah penuh terisi akan difoto kemudian foto tersebut akan dijadikan sebagai masukan untuk tahap marking. Pada penelitian ini akan digunakan data training yang didapatkan dari penelitian (Amato et al., 2017) yaitu data CNRPark. Data set ini merupakan kumpulan citra lapangan parkir yang telah terlabeli. Pada data ini terdapat berbagai macam keadaan cuaca mulai dari cerah dan hujan dengan ukuran masing-masing $150 \times 150$ sesuai pada Gambar 3. Untuk data testing akan digunakan data dari CNRPark yang memiliki citra ukuran 1000 x 750 yang menangkap seluruh lapangan parkir seperti Gambar 4. Foto yang telah masuk akan di proses dengan metode You Only Look Once (YOLO) V3 untuk dilakukan deteksi seluruh mobil yang ada pada foto tersebut. Arsitektur YOLO V3 digambarkan pada Gambar 5. Seluruh mobil yang terdeteksi diasumsikan memiliki posisi yang sama dengan tempat parkir yang tersedia sesuai dengan Gambar 6.

Pada tahap ini, hasil dari proses YOLO V3 akan difokuskan untuk mencari objek mobil. Setelah didapatkan objek mobil, penelitian akan mengambil properti dari setiap bounding box mobil yang ada pada lapangan parkir tersebut. Bounding box akan dipakai sebagai penanda posisi-posisi tempat parkir mobil yang ada pada gambar tersebut. Bounding box tersebut memiliki properti yaitu x, $\mathrm{y}, \mathrm{W}, \mathrm{H}$, dan confidence. Nilai $\mathrm{x}$ dan y merupakan posisi titik pusat dari bounding box. Nilai $\mathrm{W}$ dan $\mathrm{H}$ merupakan nilai panjang dan lebar dari bounding box. Nilai confidence merupakan nilai keakuratan deteksi objek yang terdeteksi. Properti dari bounding box yang terdeteksi tersebut akan disimpan sebagai lokasi tempat parkir untuk tahap klasifikasi dimana bounding box tersebut akan dideteksi ada atau tidaknya mobil pada tempat parkir tersebut. Tahap klasifikasi merupakan tahap penentuan tempat parkir yang telah didapatkan dari tahap marking. Klasifikasi akan menentukan tempat parkir tersebut tersedia atau tidak. Proses tahap Klasifikasi digambarkan pada Gambar 7.

Video dari kamera CCTV akan digunakan sebagai masukan. Video masukan tersebut akan diproses marking lokasi tempat parkir berdasarkan bounding box yang didapatkan pada tahap marking. Setelah bounding box itu diterapkan pada video CCTV, masing-masing bounding box bertugas untuk mendeteksi apakah ada mobil pada tempat parkir tersebut dengan cara memproses masing-masing bounding box dengan arsitektur CNN yang telah ada yaitu Alexnet, VGG 16, dan Googlenet. Penggunaan metode deteksi menggunakan $\mathrm{CNN}$ dalam mendeteksi ketersediaan tempat parkir ini agar dapat diketahui secara akurat. Jika terdapat mobil pada bounding box tersebut, maka pada proses selanjutnya, bounding box tersebut akan berubah warna menjadi merah. Sebaliknya, jika tidak terdapat mobil pada bounding box tersebut, maka bounding box tersebut akan berwarna hijau. Hasil akhir dari proses ini adalah video CCTV 
yang memiliki bounding box yang dapat menentukan tempat parkir tersebut kosong atau tidak.

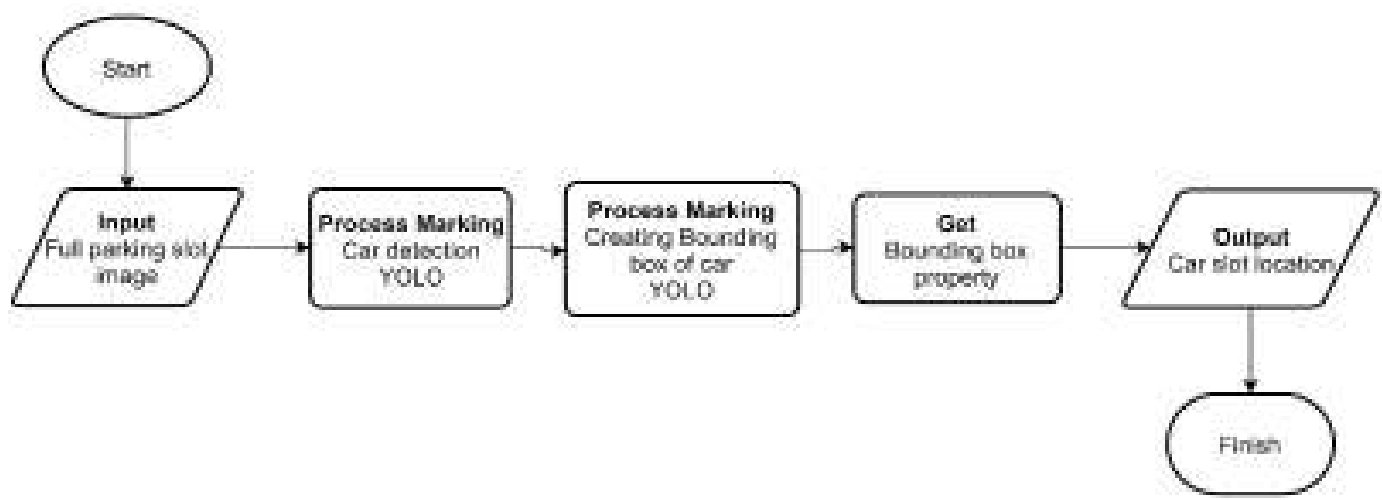

Gambar 2. Algoritma proses marking deteksi tempat parkir mobil
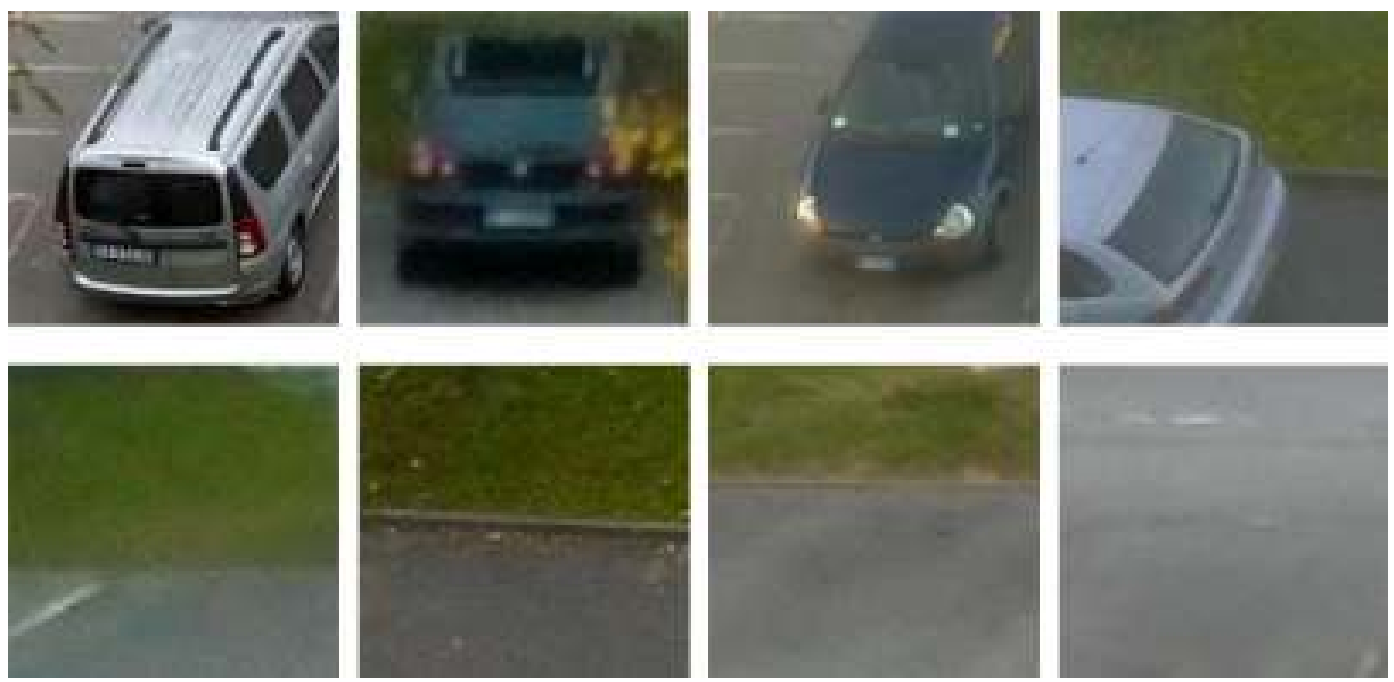

Gambar 3. Dataset CNRPark (Amato et al., 2017)

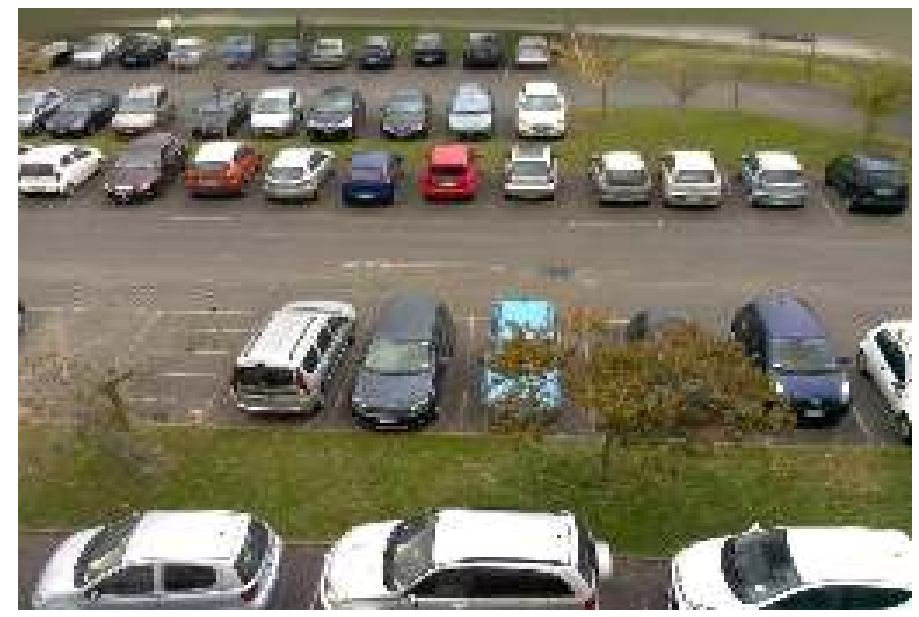

Gambar 1 Citra Lapangan Parkir CNRPark (Amato et al., 2017) 


\begin{tabular}{|c|c|c|c|c|}
\hline & Type & Fulters. & Size & Output \\
\hline & Convolutional & 32 & $3 \times 3$ & $250 \times 256$ \\
\hline & Convolutional & 64 & $3 \times 3 / 2$ & $128 \times 128$ \\
\hline \multirow{3}{*}{$1 \times$} & Corwolutional & 32 & $1 \times 1$ & \\
\hline & Comvolutionat & 64 & $3 \times 3$ & \\
\hline & Pesidual & & & $128 \times 128$ \\
\hline \multirow{4}{*}{$2 x$} & Convolutional & 128 & $3 \times 3 / 2$ & $64 \times 64$ \\
\hline & Corwolutionst & 64 & $1 \times 1$ & \\
\hline & Convolutional & 128 & $3 \times 3$ & \\
\hline & Residual & & & $64 \times 64$ \\
\hline \multirow{4}{*}{$8 x$} & Convolutionsi & 256 & $3 \times 3 / 2$ & $32 \times 32$ \\
\hline & Cormólutional & 128 & $1 \times 1$ & \\
\hline & Compolutional & 256 & $3 \times 3$ & \\
\hline & Residual & & & $32 \times 32$ \\
\hline \multirow{4}{*}{$8 \times$} & Corwolutional & 512 & $3 \times 3 / 2$ & $16 \times 16$ \\
\hline & Carvolutional & 256 & $1 \times 1$ & \\
\hline & Convolutional & 512 & $3 \times 3$ & \\
\hline & Residual & & & $16 \times 16$ \\
\hline \multirow{6}{*}{$4 \times$} & Comvolutionsi & 1024 & $3 \times 3 / 2$ & $8 \times 8$ \\
\hline & Cormolutional & 512 & $1 \times 1$ & \\
\hline & Compolutional & 1024 & $3 \times 3$ & \\
\hline & Residual & & & $8 \times 8$ \\
\hline & Avgpool & & Globsi & \\
\hline & $\begin{array}{l}\text { Connected } \\
\text { Soltmax }\end{array}$ & & 1000 & \\
\hline
\end{tabular}

Gambar 5. Arsitektur YOLO V3 (Redmon \& Farhadi, 2018)

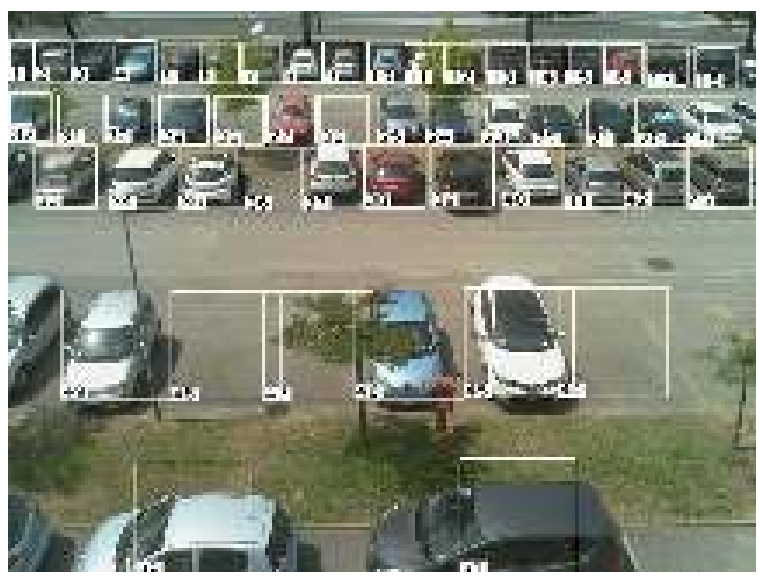

Gambar 6 Contoh posisi mobil sama dengan slot parkir (Amato et al., 2017)

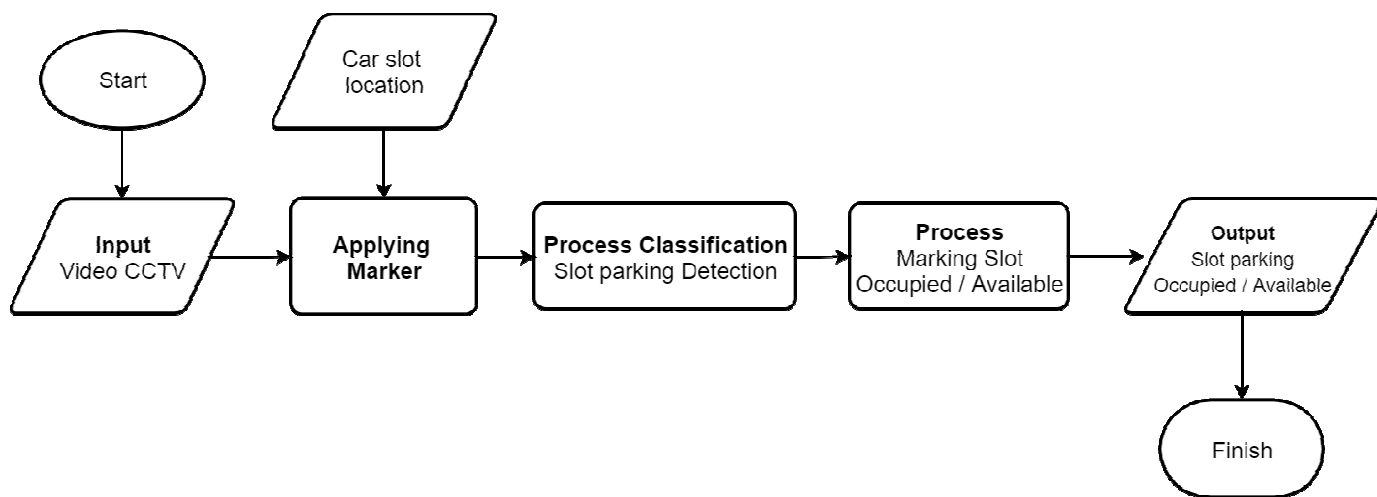

Gambar 7. Algoritma proses klasifikasi deteksi tempat parkir mobil terisi atau tidak 


\section{HASIL}

Penelitian ini menggunakan Google Colaboratory untuk menulis Pyhton dan menggunakan GPU dari Google Colaboratory untuk melakukan training dan testing model. Library yang digunakan pada penelitian ini adalah Keras dan Tensorflow.

\section{Tahap Marking}

Dalam penelitian ini, YOLO V3 untuk mendeteksi posisi mobil di tempat parkir. Metode YOLO V3 dapat mengklasifikasikan 9000 kelas objek dalam suatu gambar (Redmon \& Farhadi, 2017). Objek-objek yang dapat dideteksi seperti kendaraan, makhluk hidup, dan alat makan. Oleh karena itu, hasil dari metode YOLO V3 diproses untuk mendapatkan objek mobil dengan cara memilih objek mobil dari seluruh kelas yang terdeteksi dan kemudian mendapatkan kotak pembatas dari setiap posisi mobil.

Data yang digunakan untuk melakukan proses penandaan ini adalah gambar tempat parkir yang penuh berukuran 1000 x 750 pixel dengan warna RGB. Terdapat 6 kondisi pada Gambar 8. Lapangan parkir harus memiliki batas atau garis parkir yang jelas sehingga bounding box yang didapatkan tidak tertumpuk. Untuk menganalisis hasil dari deteksi, akan dihitung jumlah mobil yang terdeteksi dan tidak. Hasil deteksi menggunakan YOLO V3 dapat dilihat pada Tabel 1, sedangkan Gambar 8 menunjukkan hasil uji coba tahap marking.

\section{Tahap Klasifikasi}

Tahap klasifikasi merupakan tahap selanjutnya dari deteksi ketersediaan tempat parkir di mana hasil dari tahap marking digunakan untuk menandai posisi lapangan parkir yang akan di deteksi ketersediaan tempat parkir mobil pada tempat parkir yang telah ditandai. Untuk mengklasifikasikan ketersediaan tempat parkir pada tahap ini, beberapa arsitektur Convolution Neural Network (CNN) yang akan digunakan untuk mendeteksi ketersediaan tempat parkir ini adalah Alexnet, VGG16, dan Googlenet. CNN ini akan mengklasifikasikan 2 kelas yaitu terisi (occupied) atau kosong (available). Pada tahap pelatihan model, masingmasing model dilatih dengan epoch sebanyak 50 menggunakan optimizer Stochastic Gradient Descent (SGD) yang memiliki learning rate sebesar 0,01. Untuk menghitung loss dari model digunakan fungsi binary_crossentropy. Data yang digunakan untuk melakukan pelatihan model memiliki jumlah 14.032 dengan perbandingan kelas available dan occupied $50: 50$. Saat proses pelatihan, data tersebut dipisah untuk dipakai sebagai testing dengan tingkat validation split sebesar 0,1. Rata-rata hasil pelatihan dapat dilihat pada Tabel 2.

Penelitian ini menggunakan data CCTV dari lapangan parkir yang disediakan oleh CNR Park. Data tempat parkir CNR park terdiri dari gambar lapangan parkir pada waktu cerah dan hujan pada waktu pagi, siang, dan malam. Ukuran dari gambar lapangan parkir yaitu 1000 x 750 pixel. Kemudian diterapkan penanda yang didapatkan dari proses penandaan kemudian citra dari daerah yang di tandai akan di proses oleh model dan menghasilkan terisi atau tidak.

Tabel 3 dan Gambar 9 merupakan hasil percobaan pada data CCTV CNR park. Saat pagi, arsitektur yang memiliki akurasi tertinggi adalah Alexnet dengan nilai 95,07\%. Pada kondisi siang nilai akurasi tertinggi adalah 91,89\% menggunakan CNN Alexnet. 
Tabel 1. Hasil deteksi menggunakan YOLO V3 pada tahap marking

\begin{tabular}{ccccc}
\hline Gambar & Terdeteksi & Tidak terdeteksi & Akurasi (\%) & Kondisi \\
\hline $\mathbf{1}$ & 36 & 3 & $\mathbf{9 2 , 3 1}$ & Mendung \\
\hline $\mathbf{2}$ & 29 & 1 & $\mathbf{9 6 , 6 7}$ & Mendung \\
\hline $\mathbf{3}$ & 24 & 18 & 57,14 & Hujan \\
\hline $\mathbf{4}$ & 14 & 17 & 45,16 & Malam \\
\hline $\mathbf{5}$ & 47 & 7 & 87,04 & Cerah \\
\hline $\mathbf{6}$ & 45 & 8 & 84,91 & Cerah \\
\hline
\end{tabular}

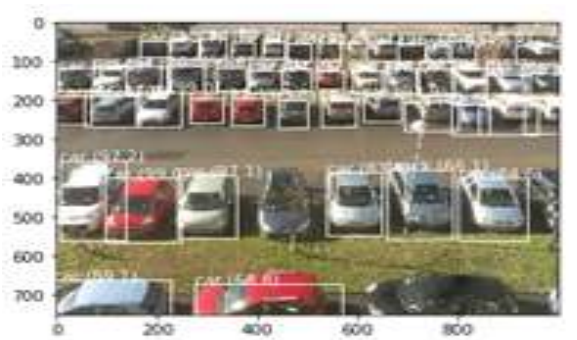

(A)

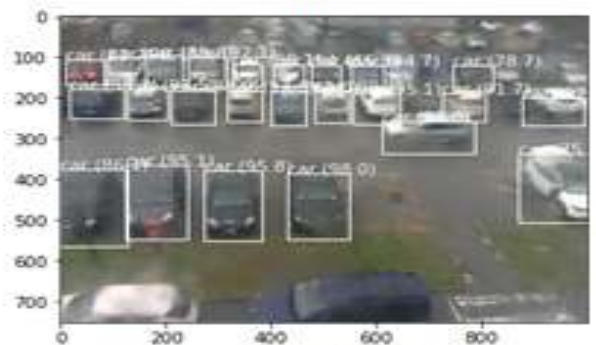

(C)

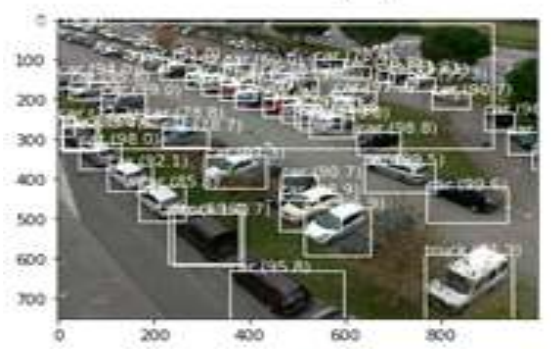

(E)

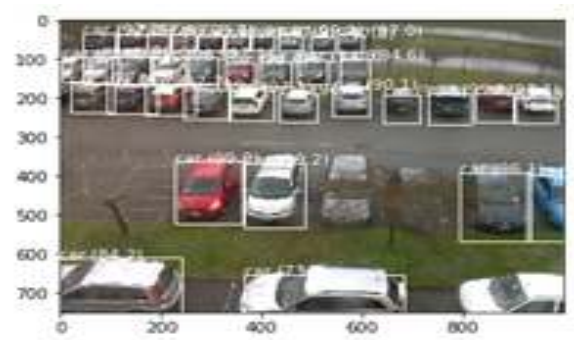

(B)

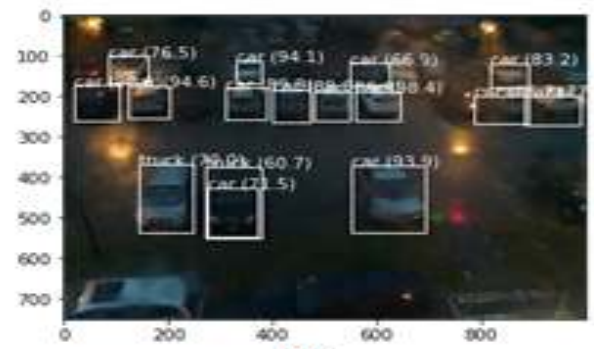

(D)

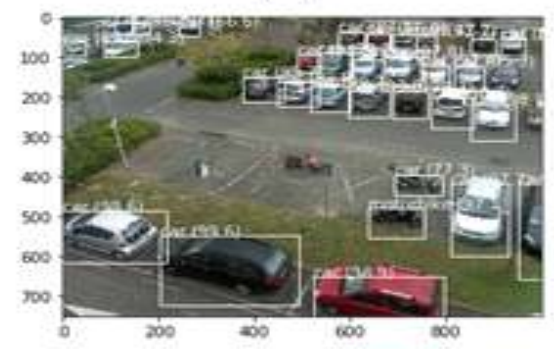

(F)

Gambar 8. Hasil bounding box dari YOLO V3 (A) cerah, (B) mendung, (C) hujan, (D) malam, dan (E) \& (F) CCTV di samping

Tabel 2. Rata-rata hasil training Lite Alexnet dan metode pembanding

\begin{tabular}{cccccc}
\hline Metode & Akurasi (\%) & $\begin{array}{c}\text { Precision } \\
(\%)\end{array}$ & $\begin{array}{c}\text { Recall } \\
(\%)\end{array}$ & $\begin{array}{c}\text { Waktu } \\
\text { (detik) }\end{array}$ & $\begin{array}{c}\text { Jumlah } \\
\text { Parameter }\end{array}$ \\
\hline Alexnet & 98,0 & 98,0 & 97,0 & 64 & 28.080 .753 \\
\hline VGG16 & $\mathbf{9 9 , 0}$ & $\mathbf{9 9 , 0}$ & $\mathbf{9 9 , 0}$ & 98 & 134.264 .640 \\
\hline Googlenet & 98,0 & 98,0 & 98,0 & $\mathbf{3 7}$ & $\mathbf{1 0 . 3 0 6 . 3 5 5}$ \\
\hline
\end{tabular}

Tabel 3 Hasil perbandingan klasifikasi CNN pada data CCTV

\begin{tabular}{ccc}
\hline & Pagi & Siang \\
\hline Metode & Akurasi (\%) & Akurasi (\%) \\
\hline Alexnet & 95,07 & 91,89 \\
\hline
\end{tabular}




\begin{tabular}{ccc}
\hline VGG16 & 95,02 & 87,84 \\
\hline Googlenet & 93,69 & 88,29 \\
\hline
\end{tabular}

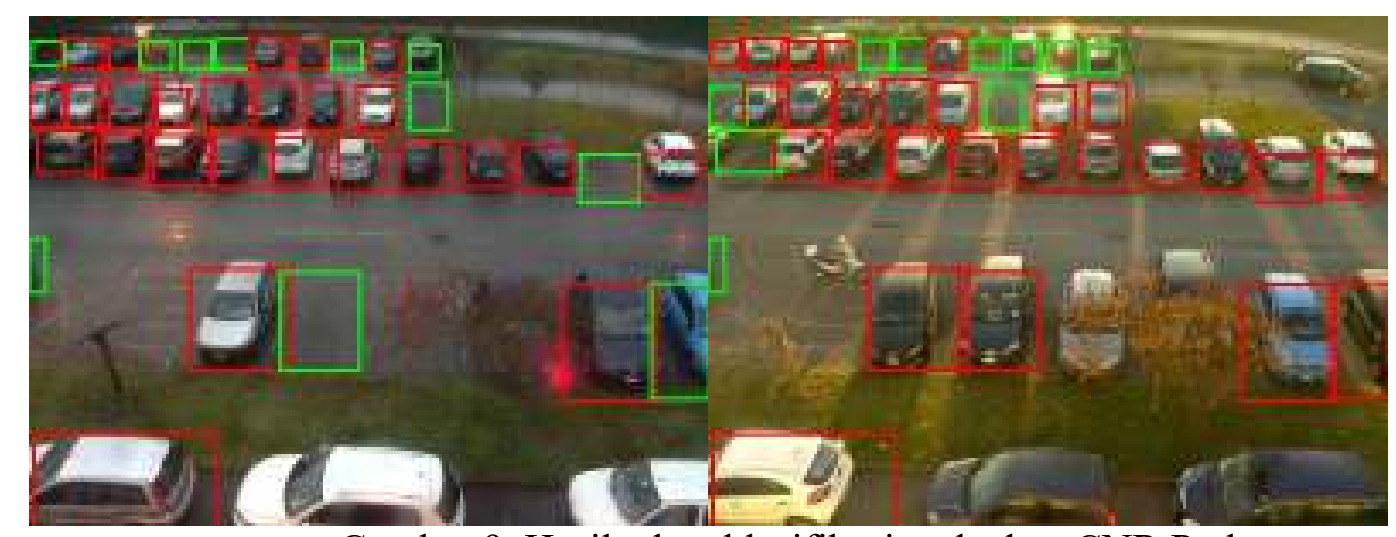

Gambar 9. Hasil tahap klasifikasi pada data CNR Park

\section{PEMBAHASAN}

\section{Tahap Marking}

Pada Tabel 1, proses pendeteksian menggunakan YOLO V3 diperoleh hasil yang baik saat cuaca mendung. YOLO V3 dapat mendeteksi objek dengan tingkat akurasi tinggi dalam kondisi mendung karena kecerahan tidak cerah dan tidak gelap, sehingga mobil terdeteksi dengan benar dengan nilai rata-rata $94,49 \%$. Saat cuaca cerah, terjadi penurunan akurasi, karena mobil putih menjadi buram akibat tingkat pencahayaan yang tinggi dengan nilai rata-rata $85,97 \%$. Skenario selanjutnya adalah menggunakan gambar tempat parkir pada malam hari. Pada malam hari akurasi dari YOLO V3 menjadi 45,16\% karena tingkat pencahayaan yang rendah dan hanya mobil yang memiliki warna-warna cerah seperti merah atau putih yang dapat dideteksi. Selanjutnya, saat hujan memiliki nilai akurasi 57,14\%. Nilai akurasi ini lebih tinggi dibandingkan dengan keadaan malam karena ada tingkat pencahayaan moderat dan ada percikan air hujan untuk menciptakan noise berupa salt and pepper.

Pada Gambar 8, terdapat empat kondisi uji coba yaitu gambar A merupakan kondisi cerah, B merupakan kondisi mendung, C merupakan kondisi hujan, dan D merupakan kondisi malam. Gambar $8 \mathrm{E}$ dan $\mathrm{F}$ merupakan contoh permasalahan yang didapatkan saat melakukan deteksi posisi tempat parkir. Gambar E diambil dari posisi serong dan mendapatkan seluruh tempat parkir pada lapangan tersebut. Akan tetapi saat dilakukan deteksi tempat parkir tersebut oleh YOLO V3, muncul masalah yaitu bentuk marker tidak dapat diputar menyerupai tempat parkir sehingga terjadi penumpukan pada posisi tempat parkir dan mobil yang lokasinya jauh dari tempat parkir tidak terdeteksi. Pada Gambar $8 \mathrm{~F}$ merupakan gambar lapangan parkir pada kondisi mendung dan dari gambar tersebut didapatkan mobil yang terpotong pada tepi gambar beberapa dapat terdeteksi akan tetapi posisi penempatan CCTV kurang optimal sehingga terjadi penumpukan bounding box pada gambar. Gambar terbaik digunakan pada tahap marking adalah gambar dalam kondisi mendung yaitu gambar B karena memiliki tingkat pencahayaan yang menengah sehingga dapat mendeteksi mobil yang memiliki warna putih dan hitam secara tepat. 


\section{Tahap Klasifikasi}

Pada Tabel 2, didapatkan waktu training dan jumlah parameter terkecil adalah Googlenet. Waktu training yang kecil ini disebabkan oleh jumlah komputasi yang kecil karena jumlah parameter pada Googlenet adalah yang paling kecil dibandingkan dengan arsitektur CNN lainnya. Sementara untuk VGG 16 mendapatkan nilai akurasi, precision, dan recall yang lebih tinggi dibandingkan dengan metode lain dikarenakan jumlah parameter yang banyak menyebabkan arsitektur tersebut dapat menarik lebih detail fitur-fitur yang ada pada tempat parkir yang telah ditandai. Akan tetapi jumlah parameter yang banyak akan menyebabkan waktu training model menjadi lebih lama. Pada kasus deteksi ketersediaan tempat parkir dapat dilihat akurasi ketiga arsitektur CNN tersebut tidak jauh berbeda antara satu arsitektur dengan arsitektur lainnya. Pada Tabel 3, hasil klasifikasi CNN menunjukkan Alexnet memiliki akurasi paling tinggi pada pagi dan siang hari, yaitu sebesar 95,07\% dan 91,89\%.

Adapun beberapa masalah yang dialami saat melakukan deteksi adalah pencahayaan tinggi karena beberapa mobil yang berwarna terang tidak dapat terdeteksi dengan baik akibat pantulan cahaya dan saat malam, mobil yang berwarna gelap susah untuk dideteksi akibat tingkat pencahayaan yang rendah. Saat hujan, data yang didapatkan dari CCTV menjadi kabur akibat adanya air hujan yang menyebabkan noise salt \& pepper sehingga mengganggu klasifikasi ketersediaan tempat parkir. Arsitektur Alexnet dapat mengklasifikasikan dalam keadaan yang memiliki tingkat pencahayaan yang menengah dan kurang memiliki noise. Sementara Googlenet dan VGG16 dapat mendeteksi lebih baik dalam kondisi gelap dan hujan karena jumlah parameter yang banyak menjadikan fiturfitur yang didapatkan lebih banyak.

\section{KESIMPULAN}

Dari hasil dan analisis penelitian ini, maka dapat disimpulkan beberapa hal. Tahap marking menggunakan YOLO V3 dapat mendeteksi tempat parkir yang ada berdasarkan posisi mobil yang ada pada citra. Citra yang terbaik untuk digunakan sebagai masukan merupakan citra lapangan parkir yang berada pada cuaca mendung karena memiliki tingkat pencahayaan yang tidak terlalu cerah sehingga mobil dapat terdeteksi secara tepat dengan nilai akurasi dengan nilai rata-rata $94,49 \%$.

Pada tahap penandaan pada YOLO V3 didapatkan bahwa mobil yang berada pada belakang objek seperti pohon ataupun mobil yang posisinya terpotong tidak dapat terdeteksi dengan baik. Pada skenario data primer, YOLO V3 dapat mendeteksi mobil akan tetapi karena posisi kamera kurang baik menimbulkan penumpukan pada tepi bounding box. Arsitktur yang memiliki nilai akurasi yang paling tinggi adalah Alexnet dengan rata-rata akurasi sebesar 93,48\%

Pada tahap klasifikasi, Arsitektur Alexnet dapat mengklasifikasikan dalam keadaan yang memiliki tingkat pencahayaan yang menengah dan kurang memiliki noise. Sementara Googlenet dan VGG16 dapat mendeteksi lebih baik dalam kondisi gelap dan hujan karena jumlah parameter yang banyak menjadikan fitur-fitur yang didapatkan lebih banyak. 


\section{SARAN}

Berdasarkan kesimpulan penelitian maka beberapa saran yang dapat diterapkan untuk penelitian berikutnya. Pertama, perlu adanya preprocessing yang dapat membantu klasifikasi mobil berwarna putih saat cuaca cerah dan sebaliknya mobil hitam saat cuaca keadaan gelap. Selain itu, penyesuaian parameter pada YOLO V3 untuk membentuk bounding box yang tidak tertimpa satu sama lain. Selanjutnya, posisi CCTV yang perlu diperhitungkan, sehingga pendeteksian ketersediaan tempat parkir mobil dapat menggunakan lebih dari satu CCTV.

\section{DAFTAR RUJUKAN}

Amato, G., Carrara, F., Falchi, F., Gennaro, C., Meghini, C., \& Vairo, C. (2017). Deep learning for decentralized parking lot occupancy detection. Expert Systems with Applications, 72, 327-334. https://doi.org/10.1016/j.eswa.2016.10.055

Borisyuk, F., Gordo, A., \& Sivakumar, V. (2018). Rosetta. Proceedings of the 24th ACM SIGKDD International Conference on Knowledge Discovery \& Data Mining - KDD '18, 71-79. https://doi.org/10.1145/3219819.3219861

Geitgey, A. (2019). Snagging Parking Spaces with Mask R-CNN and Python. Retrieved April 22, 2019, from medium.com website: https://medium.com/@ageitgey/snagging-parking-spaces-with-mask-r-cnnand-python-955f2231c400

Liang, J., Chen, X., He, M., Chen, L., Cai, T., \& Zhu, N. (2018). Car detection and classification using cascade model. IET Intelligent Transport Systems, 12(10), 1201-1209. https://doi.org/10.1049/iet-its.2018.5270

Lin, C., \& Kumar, A. (2018). Contactless and partial 3D fingerprint recognition using multi-view deep representation. Pattern Recognition, 83, 314-327. https://doi.org/10.1016/J.PATCOG.2018.05.004

Redmon, J., \& Farhadi, A. (2017). YOLO9000: Better, faster, stronger. Proceedings - 30th IEEE Conference on Computer Vision and Pattern Recognition, CVPR 2017, 2017-Janua, 6517-6525. https://doi.org/10.1109/CVPR.2017.690

Redmon, J., \& Farhadi, A. (2018). YOLOv3: An Incremental Improvement. Retrieved from http://arxiv.org/abs/1804.02767

Sugianto, N., Tjondronegoro, D., \& Tydd, B. (2018). Deep Residual Learning for Analyzing Customer Satisfaction using Video Surveillance. 2018 15th IEEE International Conference on Advanced Video and Signal Based Surveillance (AVSS), 1-6. https://doi.org/10.1109/AVSS.2018.8639478

Voulodimos, A., Doulamis, N., Doulamis, A., \& Protopapadakis, E. (2018). Deep Learning for Computer Vision: A Brief Review. Computational Intelligence and Neuroscience, 2018, 1-13. https://doi.org/10.1155/2018/7068349

Yusnita, R., Fariza, N., \& Norazwinawati, B. (2012). Intelligent Parking Space Detection System Based on Image Processing. International Journal of Innovation, Management and Technology, 3(3), 232-235. Retrieved from http://www.ijimt.org/papers/228-G0038.pdf 